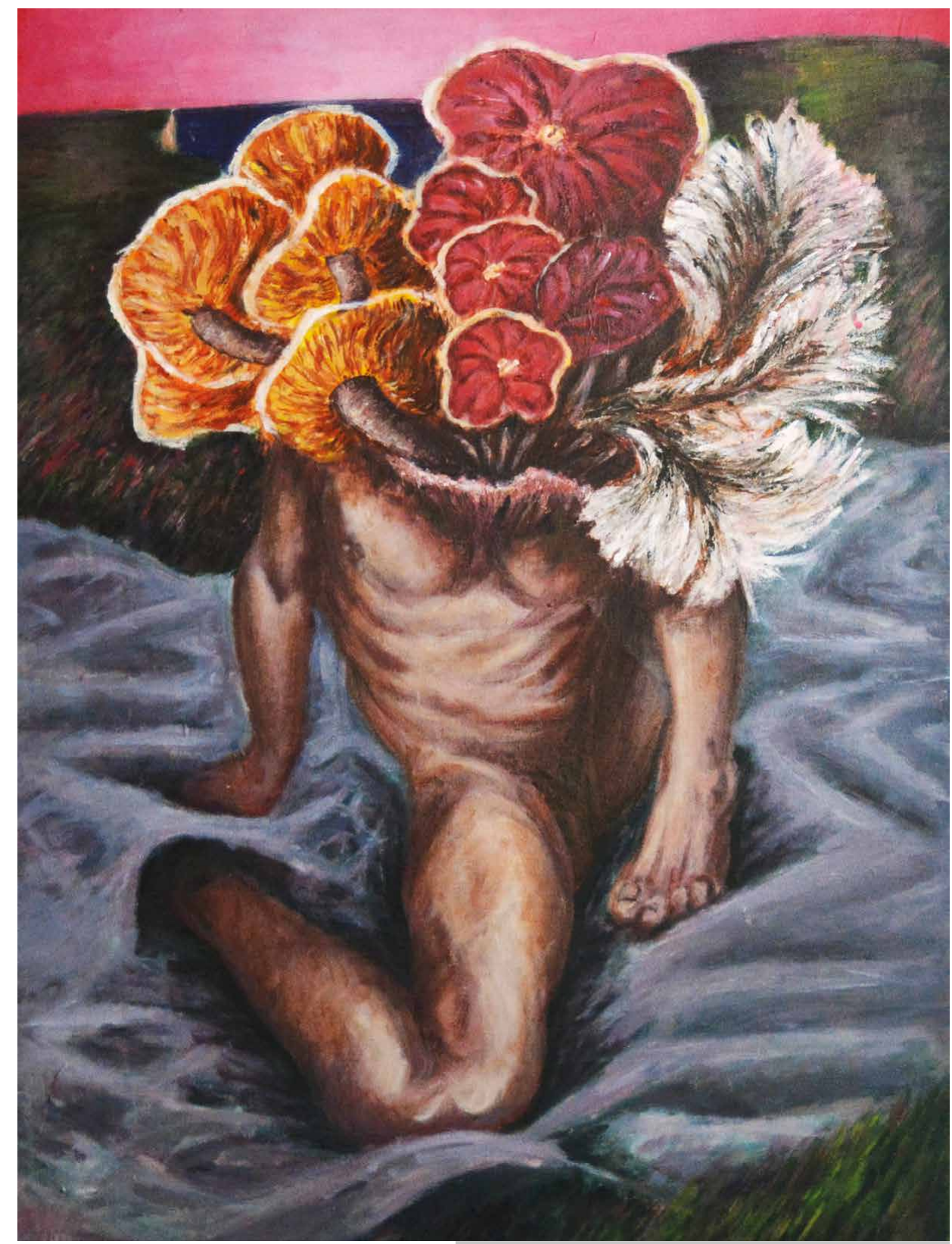

Artista invitado

Rafael Germán Rengifo Sánchez Mariposas sobre mi nariz

De la serie El jardín detrás de mi cabeza Acrílico sobre lona

$68 \times 94 \mathrm{~cm}$

2020

Medellín 


\title{
Posibilidades y riesgos de la narrativa en relaciones internacionales y ciencia política*
}

\author{
Paulo Ravecca (Uruguay)** \\ Elizabeth Dauphinee (Canadá) ${ }^{* * *}$
}

\section{Resumen}

El artículo interviene en la conversación internacional sobre las posibilidades y los límites de la escritura narrativa en relaciones internacionales y ciencia política. Concretamente, propone una comparación teórica entre «escritura fortaleza» y «voz narrativa». La primera corresponde al estilo de pensamiento y de escritura dominante en estas disciplinas. En cambio, la voz narrativa constituye una oportunidad para problematizar y aflojar los rasgos más constrictores de aquella. El artículo no propone la adopción generalizada de la escritura narrativa - proyecto inviable e, incluso, indeseable- sino que sugiere que esta última, cuando es exitosa, expande posibilidades para la investigación y la reflexión, habilitando modos menos «bélicos» de construir conocimiento. Las narrativas abren así un espacio de respiración en la academia. Sin embargo, como cualquier forma de trabajo intelectual, la escritura narrativa conlleva riesgos. En lugar de volver sobre los cuestionamientos típicos, ya extensamente contestados en la literatura, el trabajo inicia la exploración de tres riesgos que amenazan con volver a las narrativas otro tipo de escritura fortaleza: el apego a la inocencia, el apego al trauma y la cancelación moralizante de la complejidad.

\section{Palabras clave}

Relaciones Internacionales; Ciencia Política; Teoría Política; Epistemología; Investigación; Complejidad.

\footnotetext{
* Los comentarios de dos árbitros anónimos nos ayudaron a mejorar el trabajo significativamente. Errores u omisiones deben ser atribuidos únicamente a los autores.

** Politólogo. Magíster y doctor en Ciencia Política. Docente del Departamento de Ciencia Política de la Universidad de la República, Uruguay, y editor del Journal of Narrative Politics. Correo electrónico: paulo.ravecca@cienciassociales.edu.uy - Orcid: 0000-0002-9754-9520 - Google Scholar: https:// scholar.google.es/citations?user=KOoTHVMAAAAJ\&hl=es

*** Licenciada en Historia. Magíster y doctora en Ciencia Política. Profesora e investigadora del Departamento de Política de la Universidad de York, Canadá, y editora fundadora del Journal of Narrative Politics. Correo electrónico: dauphine@yorku.ca
} 
Fecha de recepción: julio de 2020

Fecha de aprobación: enero de 2021

\title{
Cómo citar este artículo
}

Ravecca, Paulo y Dauphinee, Elizabeth. (2021). Posibilidades y riesgos de la narrativa en relaciones internacionales y ciencia política. Estudios Políticos (Universidad de Antioquia), 61, pp. 231-255. DOI: 10.17533/udea.espo.n61a10

\section{Possibilities and Risks of Narrative in International Relations and Political Science}

\begin{abstract}
The article intervenes in the international conversation about the possibilities and limitations of narrative writing in international relations and political science. Concretely, it proposes a theoretical comparison between "fortress writing" and "narrative voice". The first corresponds to the style of thinking and writing that has dominated these disciplines. Instead, we show that the narrative voice constitutes an opportunity to problematize and loosen the most constrictive features of fortress writing. The text does not propose the generalized adoption of narrative writing -an unviable and even undesirable project- but suggests that, when successful, [232] narrative expands possibilities for research and reflection, enabling less "bellicose" ways of producing knowledge. Thus, narratives open a breathing space in academia. However, as with any intellectual approach, narrative writing entails some risks. Instead of engaging on common critiques, already dealt with by the literature, the essay explores three risks that threaten narrative to become another type of fortress writing: the attachment to innocence, the attachment to trauma, and the moralizing denial of complexity.
\end{abstract}

\section{Keywords}

International Relations; Political Science; Political Theory; Epistemology; Research; Complexity. 
Si el sujeto se reduce al rígido reflejo del objeto al que necesariamente falta el objeto, el cual sólo se abre al excedente subjetivo en el pensamiento, resulta el silencio espiritual sin paz de la administración integral. Únicamente una consciencia infatigablemente reificada se figura o hace creer a los otros que posee fotografías de la objetividad.

Su ilusión se transforma en inmediatez dogmática

(Adorno, 1994).

\section{Introducción}

En los últimos años la escritura narrativa ha experimentado una expansión considerable en las relaciones internacionales, irradiando también, aunque en mucho menor medida, a la ciencia política (Burnier, 2006; Ravecca, 2019a). Dado que los enfoques narrativos ofrecen posibilidades para la investigación (Ravecca y Dauphinee, 2018), este desarrollo es bienvenido; sin embargo, viene acompañado de interrogantes y desafíos en torno a la concreción de esas posibilidades anunciadas, entre los que figura la identificación de cuándo y cómo estos textos logran —o noefectivizarlas. Morgan Brigg y Roland Bleiker (2010), por ejemplo, fueron pioneros en el esfuerzo por ofrecer criterios para evaluar investigaciones autoetnográficas. Dicho esfuerzo ha sido retomado y extendido a un arco mayor de textos narrativos (Naumes, 2015). Otros autores, en su reflexión sobre el tema (Ravecca y Dauphinee, 2018) o a través de su práctica narrativa en sí misma (Öberg, 2015; 2016) expresan reticencias frente al disciplinamiento que dicha codificación, por más flexible y abierta que sea, puede acarrear.

Desde la perspectiva propuesta en este artículo, el potencial de las narrativas no puede elucidarse por medio del establecimiento de métricas de éxito y fracaso; al contrario, dicho potencial radica en la suspensión momentánea de los marcos de referencia que le dan sentido a nuestro quehacer académico. En otras palabras, el «éxito» de la reflexión narrativa se sitúa en el cuestionamiento, no solo de nuestras preguntas, sino también de los modos en que estamos entrenados y habituados a preguntar. Concretamente, se propone que el aporte central de la narrativa es que sacude lo que en otra parte hemos denominado escritura fortaleza - fortress writing - (Ravecca y Dauphinee, 2018, p. 126). 
Este artículo extiende y profundiza nuestras reflexiones previas sobre los enfoques narrativos en ciencia política y relaciones internacionales (Dauphinee, 2013; Ravecca y Dauphinee, 2016; 2018; Ravecca, 2019a). En esta ocasión, en lugar de leer e interpretar textos narrativos específicos para identificar qué insights, perspectivas o instrumentos ofrecen para el abordaje de la política global, se procede a una comparación teórica entre voz narrativa ${ }^{1}$ y escritura fortaleza, situándolas como «tipos ideales» y «polares» de formas de entender la investigación académica.

La escritura fortaleza denota el modo de escritura, el estilo de pensamiento y la clase de «diálogo» habituales para estudiantes y profesores de ciencias sociales. Se trata de un fenómeno general de la academia contemporánea que, si bien está más cabalmente representado por el mainstream positivista, atraviesa también los enfoques críticos. La escritura fortaleza promueve la invulnerabilidad como un valor central del ethos de la investigación y del investigador. Desde la «fortaleza» nos defendemos de las perspectivas que compiten con las nuestras a la vez que las atacamos, desnudando sus vulnerabilidades en la teoría, el método y la escritura. Cualquier terreno vale para minar al adversario, siempre y cuando se sigan las reglas del buen contendiente intelectual. ${ }^{2}$

[234 ] El objetivo siempre es el mismo: demostrar que se tiene la razón y que el otro está equivocado, que nuestros argumentos se basan en la evidencia de los hechos y que la verdad está de nuestro lado. Para ello es necesario mostrar temple y racionalidad, incluso «frialdad», en el sentido de probar que el trabajo propio no está «contaminado» de emoción. Así se prueba, de paso, que se es mejor académico que los adversarios. Irónicamente, la escritura fortaleza es una dinámica beligerante, análoga al modo típicamente pesimista en que se representan las interacciones entre los actores políticos estudiados. Se asemeja, acaso, a un modelo de batalla medieval, de fortificaciones y guerreros que de tan acorazados terminan pareciéndose a un caballero de hojalata.

\footnotetext{
${ }^{1}$ Las expresiones «narrativa» y «enfoques narrativos» refieren al campo académico de producción de textos con formato narrativo. La expresión «textos narrativos» nombra los trabajos concretos en cuestión. Mientras tanto, se usa aquí «voz narrativa» para designar al estilo de pensamiento y escritura descritos en este artículo y que se oponen a la escritura fortaleza. No todos los textos narrativos presentan cada uno de los elementos que, según la conceptualización propuesta, caracterizan a la voz narrativa. Es importante reparar en la distinción entre narrativa como formato y como estilo de pensamiento. La correspondencia entre estos está lejos de ser perfecta.

${ }^{2}$ Por ejemplo, evitar los ataques ad hominem, las interpretaciones descuidadas o malintencionadas, y la atribución irresponsable de ideas o intenciones percibidas como problemáticas por las mayorías sociales o de la profesión.
} 
Hay razones sociales, institucionales, epistemológicas y hasta psicológicas que sostienen la escritura fortaleza: la hegemonía del positivismo (Jackson, 2011; Monroe, 2005), las dinámicas de competencia exacerbada institucionalmente inducidas —el tan común como cruel mandato de publish or perish-, el neoliberalismo en la universidad (Giroux, 2014; Mohanty, 2013), incluso la ansiedad de los egos académicos, tan inflados como frágiles. La intención de este artículo no es ofrecer una teorización global y completa de la escritura fortaleza, sino bosquejarla en tanto estilo dominante de escritura frente al cual la narrativa ofrece un «espacio de respiración» y formas menos bélicas de encuentro con el otro, sea el objeto de estudio, nuestro interlocutor o incluso las distintas versiones de uno(a) mismo(a).

Las narrativas ofrecen oportunidades para cuestionar la dimensión violenta de la institucionalización de la ciencia social, para criticar las condiciones en que se produce conocimiento y para confrontar los poderes -internos y externos - que regulan los análisis del poder. Sin embargo, sería irónico, además de inviable e indeseable, que en este texto se utilizara el movimiento que la narrativa encarna hacia la pluralización del saber para proponer el rechazo in toto de la escritura fortaleza y la adopción universal de la voz narrativa como la única opción válida. El argumento, por el contrario, es que la academia tiene un exceso de escritura fortaleza y que darle espacio a la narrativa abre posibilidades.

La investigación cualitativa y la teoría crítica han impugnado la escritura fortaleza —aunque, claro está, sin llamarle de este modo- de diversas maneras y en distintos tiempos. Piénsese en la filosofía de Friedrich Nietzsche, en el feminismo, en los estudios poscoloniales o en los más recientes estudios críticos de discapacidad (Clare, 2017). En algunos casos, estos enfoques son responsables de haber introducido la narrativa en sus campos de estudio correspondientes. La intervención que el presente trabajo efectúa cobra sentido a la luz de ese panorama más amplio. ${ }^{3}$ Además -la aclaración es crucial - ninguna rúbrica o estilo de trabajo garantiza praxis intelectuales o políticas: así como una teoría crítica puede caer en dogmatismos (Rieiro, Rinesi, Ravecca, 2019), un texto narrativo no necesariamente logra ejercer la voz narrativa en plenitud, y ambas pueden transformarse en un ejemplo de escritura fortaleza. No hay panaceas ni soluciones prefabricadas para las rigideces de la academia.

\footnotetext{
${ }^{3}$ Las relaciones internacionales como disciplina han sido particularmente hospitalarias para programas de investigación que cuestionan la escritura fortaleza incorporando cine, literatura, teatro y las artes en general. En este sentido es importante destacar que la narrativa «no está sola» y que se inscribe en un paisaje intelectual amplio y rico (Ravecca y Dauphinee, 2018).
} 
Hechas las anteriores precisiones, el argumento propuesto es que la narrativa, dada la naturaleza de su metodología y, en particular, su forma literaria, no puede universalizar su punto de vista ni imponer una verdad monolítica y estable. Este rasgo, usualmente visto como una debilidad, permite que los términos del encuentro — con el otro y entre texto y lectura-, así como la forma misma de concebir la investigación, puedan ser problematizados. Esta posibilidad de repensar los términos mismos de la conversación académica contribuye a mantener la imaginación democrática de nuestras disciplinas. Ahí radica la fortaleza de las narrativas. El escritor o la escritora puede acaso narrar autoritariamente, pero la lectura puede siempre «sorprender» al texto con nuevos significados, con nuevas versiones e interpretaciones de la realidad narrada. Este diálogo abierto no está disponible en el formato de investigación de la academia oficial — frecuentemente tampoco en el de sus alternativas «críticas»— donde se puede señalar fallas e identificar errores en un texto, pero no resignificar la historia que cuenta.

En los siguientes apartados se desarrolla la comparación entre escritura fortaleza y voz narrativa en tanto tipos ideales de escritura, poniendo énfasis en las posibilidades que la segunda ofrece. Luego se exploran tres riesgos potenciales de la escritura narrativa. Se dejan a un lado los defectos que típicamente se le han endilgado - particularmente, autoindulgencia, sentimentalismo, falta de objetividad y ausencia de rigor- porque estos han sido ampliamente relativizados y problematizados por la literatura especializada (Brigg y Bleiker, 2010; Dauphinee, 2013; Dauphinee y Inayatullah, 2016; Inayatullah, 2011; 2020, mayo 4; Naumes, 2015; Ravecca, 2019a). En lugar de eso, la reflexión de cierre se enfoca en problemas teóricos del contexto actual: el apego a la inocencia, el apego al trauma y la cancelación moralizante de la complejidad.

\section{Escritura fortaleza y voz narrativa: dos formas de habitar la investigación}

Ha sido solo recientemente que la narrativa se ha hecho un lugar legítimo en las relaciones internacionales, adquiriendo, incluso, cierto grado de popularidad (Naumes, 2015, p. 828). En la ciencia política la renuencia ha sido la norma. Esto puede explicarse por su rechazo a los insights críticos vagamente identificados con el «posmodernismo» y por su adopción —a veces dogmática - de cánones metodológicos positivistas. Incluso la teoría política, una subdisciplina tradicional de la ciencia política, vive en una situación de 
perenne marginalidad (Brown, 2011; Monroe, 2005), la cual es aún más aguda en América Latina (Ravecca, 2019a; Ravecca y Rossello, 2020). En todo caso, la publicación de textos narrativos que tematizan algún aspecto de lo político no ha dejado de intensificarse $y$, sin dudas, el lanzamiento del Journal of Narrative Politics en 2014 marcó un antes y un después en este proceso.

Véanse, por ejemplo, el foro sobre autoetnografía del Review of International Studies (36) 3, julio 2010; Autobiographical International Relations de Naeem Inayatullah (2011); Politics of the Trail de Oded Löwenheim (2012); Politics of Exile de Elizabeth Dauphinee (2013); The Colonial Signs of International Relations y Politics in Emotion: The Song of Telangana de Himadeep Muppidi (2013; 2016); Is All "I" IR? de Sarah Naumes (2015); Security Dialogue, (44) 4, Special Issue on Elizabeth Dauphinee's The Politics of Exile, agosto 2013; Aesthetics and World Politics de Roland Bleiker (2009); y Narrative and the Possibilities for Scholarship de Paulo Ravecca y Elizabeth Dauphinee (2018). La tradición feminista en general ha desempeñado un rol significativo en la incorporación de la narrativa a las relaciones internacionales (Ravecca y Dauphinee, 2018). En América Latina, la revista de teoría política Crítica Contemporánea, 6, 2016, publicó un dossier titulado Ideas que solo se pueden contar: narrativa (y) política, el cual contiene ensayos narrativos en español, inglés y portugués.

Estos textos son diversos en su contenido, estilo y estructura, y no todos pueden ser clasificados como autobiografías o autoetnografías; no obstante, las narrativas académicas suelen trabajar en la intersección entre un yo que escribe y (auto)reflexiona, una mirada crítica a las dinámicas de poder en la academia y el conocimiento profundo de un área, tema o problema particular (Ravecca y Dauphinee, 2016).

En Ravecca y Dauphinee (2018, p. 127) se oponen los enfoques narrativos a la escritura fortaleza, a la cual se define como un estilo de pensamiento que concibe al «éxito» del par investigador-investigación en términos de su invulnerabilidad. En contraste, se sitúa la voz narrativa alrededor de temas como la apertura, la contradicción, la ambigüedad, la fractura, la sorpresa y la ingobernabilidad de la vida política e intelectual. En esta conceptualización, más que competir con la ciencia social tradicional, las narrativas ofrecen una mirada potente hacia la complejidad y hacia la pluralidad de la realidad social. 
Enesteartículoseexpandenesasreflexionesyseproponeunacomparación teórica entre escritura fortaleza y voz narrativa, conceptualizándolas como tipos ideales o polares de formas de entender la investigación académica. ${ }^{4}$ Para ello, el cuadro 1 las contrasta de forma sistemática. Resulta pertinente subrayar que este procedimiento pierde los matices y hasta cierto punto ejerce la lógica binaria que se quiere resistir. Adicionalmente presenta la desventaja de que asocia escritura fortaleza a positivismo cuando, en realidad, si bien este es quizá el epítome de aquella, la voz narrativa también desafía modos convencionales de producir pensamiento crítico. ${ }^{5}$ Sin embargo, el ejercicio es apropiado para organizar de forma clara ideas que son abstractas y complejas, especialmente teniendo en cuenta que el objetivo aquí no es practicar la narrativa sino teorizarla. De todos modos, habrá oportunidad de reintroducir matices y de trascender el binarismo del razonamiento a la hora de discutir los riegos de la escritura narrativa.

Cuadro 1. Comparación teórica entre escritura fortaleza y voz narrativa

\begin{tabular}{|l|l|}
\hline Características de la escritura fortaleza & \multicolumn{1}{|c|}{ Características de la voz narrativa } \\
\hline $\begin{array}{l}\text { El conocimiento está separado de la } \\
\text { vida social y personal }\end{array}$ & $\begin{array}{l}\text { El conocimiento no está separado de la vida } \\
\text { social ni personal }\end{array}$ \\
\hline Objetividad y neutralidad & $\begin{array}{l}\text { Pone en juego al yo en relación con otros; } \\
\text { implicación subjetiva e ideológica }\end{array}$ \\
\hline Apego a la verdad & Multiplicidad y movilidad de la verdad \\
\hline Defensa y ataque (guerra) & Vulnerabilidad y hospitalidad (diplomacia) \\
\hline $\begin{array}{l}\text { Linealidad: orientación a un objetivo } \\
\text { predeterminado y claro }\end{array}$ & Apertura: multiplicidad de la exploración \\
\hline $\begin{array}{l}\text { Control (de los conceptos, de las } \\
\text { variables, de los datos, entre otros) }\end{array}$ & $\begin{array}{l}\text { Ingobernabilidad (de los conceptos, de las } \\
\text { variables, de los datos, entre otros) }\end{array}$ \\
\hline $\begin{array}{l}\text { Busca extraer («extractivisimo» que } \\
\text { mantiene a la fortaleza desde la cual se } \\
\text { escribe) }\end{array}$ & $\begin{array}{l}\text { Trae diferentes formas epistemológicas de ser en } \\
\text { el mundo }\end{array}$ \\
\hline
\end{tabular}

\footnotetext{
${ }^{4}$ Así como no todos los textos narrativos coinciden con la voz narrativa, tampoco todos los textos en otros formatos pueden ser reducidos a escritura fortaleza.

${ }^{5}$ Además, la escritura fortaleza se cuela por los esfuerzos por resistirla porque las dinámicas de la profesión conducen a ella una y otra vez. Por eso este trabajo refiere a tipos ideales o polares. La voz narrativa no es una «cosa» o un procedimiento preestablecido o prefabricado, sino un horizonte de posibilidad. Agradecemos a uno de los pares evaluadores por hacer notar la importancia de diferenciar escritura fortaleza de positivismo.
} 
Posibilidades y riesgos de la narrativa en relaciones internacionales y ciencia política

Cuadro 1. (Continuación)

\begin{tabular}{|l|l|}
\hline Características de la escritura fortaleza & \multicolumn{1}{|c|}{ Características de la voz narrativa } \\
\hline Métricas claras de éxito y fracaso & Indeterminación de métricas de éxito y fracaso \\
\hline $\begin{array}{l}\text { Búsqueda de lenguaje claro y } \\
\text { transparente }\end{array}$ & $\begin{array}{l}\text { Somos perpetuos inmigrantes en el lenguaje; } \\
\text { fallamos en nuestros intentos de traducción }\end{array}$ \\
\hline $\begin{array}{l}\text { Es preciso resolver la ambigüedad y la } \\
\text { contradicción }\end{array}$ & $\begin{array}{l}\text { Hay la posibilidad de sostener la ambigüedad y la } \\
\text { contradicción }\end{array}$ \\
\hline La sorpresa como problema & La sorpresa como oportunidad \\
\hline $\begin{array}{l}\text { Separación en dimensiones: cultura, } \\
\text { economía, política; e incluso más } \\
\text { específicas: políticas públicas, literatura } \\
\text { mexicana del siglo xix, entre otros }\end{array}$ & $\begin{array}{l}\text { Multidimensionalidad (una historia -story- no } \\
\text { separa en dimensiones) }\end{array}$ \\
\hline $\begin{array}{l}\text { La academia como el todo ausente (no } \\
\text { se cuestiona) }\end{array}$ & La academia como lugar (se cuestiona) \\
\hline $\begin{array}{l}\text { Los otros de la ciencia son excluidos, } \\
\text { estudiados o controlados }\end{array}$ & $\begin{array}{l}\text { Los otros de la ciencia se hacen lugar } \\
\text { (sentimientos, intuiciones, espiritualidad, saberes } \\
\text { populares, expresiones artísticas, entre otros) }\end{array}$ \\
\hline $\begin{array}{l}\text { Exterioridad de la lectura; relación } \\
\text { distante y hostil con el texto }\end{array}$ & $\begin{array}{l}\text { Interioridad de la lectura; puede sorprender al } \\
\text { texto, rescatarlo cuando falla }\end{array}$ \\
\hline
\end{tabular}

Fuente: elaboración propia.

\section{Escritura fortaleza}

Cualquiera que haya pasado por un curso de metodología sabe que, para el mainstream de la ciencia política y las relaciones internacionales, la producción de conocimiento debe estar resguardada de los avatares de la vida personal y, por supuesto, de la política. Esta separación es imprescindible para lograr objetividad y neutralidad, condiciones sine qua non de la ciencia. Subjetividad y academia son incompatibles. Tanto las emociones como las perspectivas ideológicas del investigador son una carga molesta e incluso peligrosa que tienen que ser vigiladas, si no evacuadas, de la labor científica.

La ciencia tiene como objetivo la búsqueda de la verdad, aún si ésta se define — en gesto de renovación positivista — por aproximaciones provisorias. La carrera por llegar primero al podio de la verdad se transforma en justa: atacamos y nos defendemos. Defendemos nuestros argumentos y teorías, 
incluso de críticas imaginarias o por venir; atacamos la investigación previa, mostramos qué hay de defectuoso en ella y —si se tiene éxito- «llenamos» un vacío en el estado actual del conocimiento: conquistamos un tramo de la realidad previamente desconocido y, por así decir, le ponemos nuestro nombre. De ese modo nos hacemos de un lugar en la academia internacional.

Paradójicamente, mientras que el estudioso de la política tiene que ser neutro y objetivo, el «diálogo» que establece con sus pares científicos parece ser un reflejo de cómo el conflicto opera «allá afuera». Esto aplica también a la teoría crítica que, no obstante sus críticas al positivismo reinante, participa plenamente de esta dinámica beligerante y muchas veces tiene que volverse «eficiente» $y$ «operativa» para poder sobrevivir.

El argumento de un texto académico debe ser preciso y contundente. Las ideas centrales están definidas de antemano y no deben cambiar en el transcurso de la escritura. La función de la escritura es trasmitir lo que ocurrió «por fuera» de ella. La escritura es un vehículo, no un ejercicio de experimentación con el pensamiento. De hecho, no hay experimentación con el pensamiento porque los conceptos y los datos tienen que estar bajo control, y la propia experimentación, cuando la hay, sigue el modelo naturalista que [240] implica un reforzamiento del control, no su cuestionamiento.

Complementariamente, se suele entablar un vínculo «extractivista» con el objeto de análisis: el sujeto que piensa sale al mundo a recoger los datos que precisa para contrastar sus teorías. La colegialidad que construye con sus informantes o con sus sujetos de investigación está limitada por las reglas que regulan ese encuentro, lo cual también remite a la supresión de la subjetividad y de las emociones. Las experiencias humanas registradas son reducidas a datos para probar las hipótesis de investigación. El otro deviene cosa.

Las métricas de éxito y fracaso son transparentes e indiscutibles. La evaluación del texto y de la investigación que este pone en palabras viene con preguntas predefinidas, del tipo: ihay una definición correcta, pertinente y precisa del marco teórico?, ¿se utiliza de modo apropiado la metodología?, iresponden los hallazgos a las preguntas planteadas? Las equivocaciones pueden transformarse en momentos de aprendizaje, siempre que no refieran a una falla de diseño o a una ejecución pobre por parte del académico. En el lenguaje popularizado del falsacionismo popperiano, la falsación de una hipótesis expande el conocimiento. Así, los errores son neutralizados y 
domesticados reforzando el control y la validez de nuestra posición inicial. Las preguntas en torno al texto en sí mismo rondarán asuntos como la claridad de la prosa, la profesionalidad del fraseo y la solidez de la estructura. Como una entrevistada en Ravecca (2019) señaló, a los estudiantes se les exigirá purgar el lenguaje «demasiado poético».

De dicha observación emerge la inquietud acerca de qué voces se están acallando cuando se impone la tabula rasa de los criterios dominantes de exposición. La purga lingüística es también epistemológica. La búsqueda de una escritura lineal, precisa y transparente tiende a negar la complejidad. Herbert Marcuse (1991) ya había teorizado persuasivamente las transformaciones de la escritura en la academia norteamericana, donde se había impuesto «una sintaxis en la que la estructura de la frase es comprimida y condensada de tal modo que no se deja ninguna tensión, ningún "espacio" entre sus distintas partes» (p. 86). Su crítica apuntaba al conductismo, al empirismo y al positivismo correspondientes a lo que llamó sociedad unidimensional. Sin embargo, ese estilo de escritura ha penetrado la academia en general, incluyendo la teoría crítica (Rieiro, Rinesi y Ravecca, 2019), particularmente en esta coyuntura histórica que parece despreciar la incertidumbre, la paradoja, la hermenéutica, la ambigüedad y la complejidad.

Dicho desprecio remite al estatuto epistemológico de la sorpresa. El espíritu científico que se encuentra en las biografías de grandes personajes del saber universal está atravesado por el espíritu lúdico, por la curiosidad y por la posibilidad de básicamente reverlo todo. Sin embargo, la universidad actual y las revistas académicas no parecen dejar mucho espacio para la búsqueda arriesgada ni para la sorpresa radical que deshace nuestra propia Weltanschauung — cosmovisión- La prosa segura y sin fisuras de la escritura fortaleza no conduce a la novedad. A este respecto ha habido interesantes discusiones acerca del arbitraje ciego (Traversa, s. f.). En este contexto tiene sentido preguntarse qué le pasa a la creatividad si el único modelo de pensamiento válido apunta a la invulnerabilidad.

El trabajo académico suele dividir la realidad en «campos» nítidamente diferenciados: política, economía, cultura, y sociedad. Explicar o evaluar este desarrollo excede el propósito de este artículo, pero entre sus causas pueden señalarse las dinámicas mismas de la modernidad tardía y su fusión con el liberalismo (Brown, 1995), la especialización y división del trabajo intelectual, y la profesionalización disciplinaria problematizada, por ejemplo, por Pierre 
Bourdieu. Si bien la teoría crítica ha discutido el carácter ideológico de esa segmentación, la propia mecánica del trabajo intelectual en la universidad de hoy la empuja a su reproducción —nótese que son escasas las revistas de teoría crítica realmente interdisciplinarias-. Dicha fragmentación es defendida y justificada con niveles más o menos elevados de sofisticación. En el caso de la ciencia política latinoamericana se tiende a abrazar una versión simple, reificada y literal de la «autonomía de la política» en que esta última está separada de lo social por una especie de alambrado imaginario.

Estas divisiones refuerzan la impresión de claridad, orden y control, y la escritura fortaleza las naturaliza a un alto costo. Más abajo se explora cómo las narrativas son una oportunidad de recordar que la realidad no «es» estas divisiones y que, por el contrario, la misma está constituida por un conjunto inabarcable de relaciones que no respetan las fronteras que nuestras profesiones — «Críticas» o no- han impuesto, a veces antojadizamente.

Esta sección comenzó señalando que para la escritura fortaleza la ciencia está separada de la vida que estudia, para luego señalar que, a su vez, la ciencia segmenta la realidad en partes. No es de sorprender que, en esta lógica, la academia quede separada de la política. Las instituciones académicas

[242] son concebidas como plataformas neutras e inocuas desde donde el mundo es analizado objetivamente $y$, por lo tanto, no tiene sentido estudiarlas ni cuestionarlas. Para la escritura fortaleza la autorreflexión es un ejercicio manierista propio de disciplinas «no científicas» tales como el psicoanálisis. En este marco las relaciones de poder dentro de la ciencia y de la academia devienen invisibles. Obviamente, esto también inhabilita cualquier reflexión más o menos sutil acerca de la relación entre ciencia e ideología. Es frecuente que en la academia oficial latinoamericana ideología y análisis se piensen como meros antagónicos sin ningún sentido de complejidad. Cuando se trata del poder, estamos entrenadísimos para ver la paja en el ojo ajeno y para invisibilizar la viga en el propio.

Además de la subjetividad y la ideología, hay estilos de pensamiento y actividades humanas que, de acuerdo con la escritura fortaleza, constituyen una amenaza para el pensamiento «serio» y de las cuales la ciencia debe desmarcarse constantemente. Entre esas otredades defectuosas figuran el arte, la religión, las prácticas y saberes populares, y el misticismo. Al decir de Naeem Inayatullah (2011, p. 7), la ciencia tiene un objetivo propio del 
místico: explicar la vida en su plenitud. Sin embargo, en tanto personas de ciencia, excluimos las herramientas del místico: la poesía, la danza, la música, y la meditación contemplativa.

Por último, en el marco de la escritura fortaleza la lectura está concebida como externa al texto. El lector evaluará su calidad y emitirá un juicio. El objetivo de la escritura es, por tanto, persuadirlo. Para ello el texto debe estar blindado contra toda crítica — no mostrar fisuras ni flancos débiles-e incluso hacer ataques preventivos contra objeciones potenciales. También debe controlar y estabilizar al máximo su propio significado, no dejando piezas sueltas para la «libre interpretación». La ambigüedad y polisemia del lenguaje han de minimizarse para suprimir dicho margen de libertad en la lectura, porque ésta puede traducirse en críticas - entendidas como ataques- y en el socavamiento de la significación del texto. La confusión, la contradicción, el fracaso y la sorpresa no devienen en momentos de aprendizaje ni se traducen en un encuentro de colegialidad. Más bien se traducen en rechazos — de revistas académicas, por ejemplo- y en el abandono del proyecto en cuestión. Paradójicamente, el encuentro entre texto y lectura, además de estar detalladamente normado, es más bien hostil y árido. El talante bélico de dicho encuentro imposibilita la mutua transformación o una búsqueda abierta. Las vías de acceso entre texto y lectura están cuidadosamente señalizadas y no se pueden reinventar.

En resumen, la escritura fortaleza gira en torno a la separación como principio regulador de la actividad intelectual. En esta sección hemos recorrido la serie de separaciones a la que la actividad académica queda sometida respecto de la vida social y personal, de las emociones, de las relaciones de poder, y entre texto y lectura-. Esta suerte de aislamiento aséptico lleva a una escritura «estéril» (Naumes, 2015).

Lejos se está de aquel «rumiar» filosófico ofrecido por Nietzsche (1989) y en particular de sus metáforas tan llenas de vitalidad y epistemología, como la de caminar a tientas por terrenos que - como el de la propia moralidadde tan familiares se habían vueltos misteriosos y requerían ser recorridos con pies y ojos nuevos. Lejos también se está ahora de ese encuentro intenso y emocional al que el autor invitaba a sus lectores. Para la escritura fortaleza la ciencia no es riesgo y creación, sino seguridad y mecánica. 


\section{Voz narrativa}

Distintas tradiciones de pensamiento crítico han hecho esfuerzos por problematizar la escritura fortaleza. Por ejemplo, la separación entre conocimiento y vida - personal y colectiva - ha sido objeto de sendos cuestionamientos. Para el propio Karl Marx (1978) la producción de saber constituía una «actividad humana» atravesada por los avatares de la historia que ella trataba de aprehender. Después de todo, el autor razonaba, hasta el lenguaje movilizado en el pensamiento viene dado por otros. Esta concepción ha sido enriquecida por distintas versiones de neomarxismo y posmarxismo, las cuales han identificado al propio principio de objetividad científica como una plataforma epistemológica que invisibiliza $-y$ sostiene- formas de opresión en nombre de la ciencia. En este sentido, la Escuela de Frankfurt es paradigmática (Horkheimer, 1978; Marcuse, 1991).

La exploración del vínculo entre conocimiento, poder y subjetividad ha sido ampliada en nuevas direcciones por la epistemología feminista, los estudios queer, los enfoques pos y decoloniales, y los estudios críticos de discapacidad. ${ }^{6}$ Este artículo sitúa a la voz narrativa en este panorama contemporáneo de teorías alternativas; sin embargo, en la perspectiva [244] aquí propuesta, aquella radicaliza la crítica al «distanciamiento ficcional» (Inayatullah, 2011) de la ciencia social dominante. E incluso más: la narrativa muestra cómo las alternativas al mainstream suelen terminar pareciéndosele demasiado (Ravecca y Dauphinee, 2018). Esto apunta a la sospecha de que el funcionamiento de la academia contemporánea en sí mismo induce a la escritura fortaleza sin reparar en epistemologías alternativas o banderías radicales de tipo alguno. Por ello el ejercicio propuesto aquí concibe a la vOz narrativa como un horizonte abierto de potencialidad, más que como una teoría autocontenida o como una serie de procedimientos que vienen a sustituir al establishment.

La escritura académica no puede desembarazarse del sujeto ni de su subjetividad, por más que haga — como suele hacer- esfuerzos titánicos en ese sentido. El «yo» que crea y trae conocimiento al mundo es, a su vez, inseparable de sus relaciones con otros y de sus circunstancias (Pin-Fat, 2016). Esto afecta no solo los temas que se eligen para explorar (King, Keohane y Verba, 2000), sino también cómo se los estudia, qué se ve y qué conocimiento

${ }^{6}$ El capítulo primero de Ravecca (2019) realiza un recorrido por distintas formas en que la teoría crítica ha tematizado la relación entre el conocimiento y el poder. 
se genera. Como se señala en la primera celda a la derecha del cuadro 1, la narrativa encarna esta inseparabilidad entre escritura, subjetividad y contexto, y por eso resiste el borrón de la vida en el acto de conocer. Evidentemente, las relaciones de poder forman parte del contexto que afectan al sujeto que escribe. La neutralidad que el mainstream de las ciencias sociales pretende no es solo un asunto epistemológico, porque naturaliza desigualdades dentro y fuera de la universidad. Las narrativas ofrecen una alternativa que desembrolla los anudamientos entre poder y verdad que tanto obsesionaban a Michel Foucault.

El problema del poder será abordado nuevamente más adelante. Por ahora interesa subrayar que aceptar que nuestras perspectivas son inseparables de nuestras experiencias en el mundo implica la pérdida irremediable de cualquier pretensión de alcanzar «la verdad». Más que una verdad alternativa - como en el caso de la mayoría de las teorías críticas- el resultado aquí es la admisión de la precariedad y limitación de cualquier punto de vista. La verdad que la narrativa puede ofrecer es móvil, situada y relacional. Esto, lejos de ser una abdicación relativista, es un gesto pluralista y diplomático en el terreno del pensamiento. El mundo es epistemológicamente diverso. La voz narrativa se entiende, entonces, como un modo de encuentro que activa la hospitalidad y la diplomacia entre subjetividades en ese entorno de diferencia y multiplicidad. En este marco, la forma en que el debate académico es estructurado frecuentemente — defensa y ataque — pierde pie. Las narrativas (nos) dan permiso para ser vulnerables, para dudar y para pensar y crear con otros. En este sentido, no obstante compartir el cuestionamiento de la verdad y sus efectos de poder, la voz narrativa contrasta con el legado de Foucault y su fijación en la dominación y la resistencia.

Otro legado crítico frecuentemente convocado en las conversaciones sobre ciencia, subjetividad y verdad es el de Pierre Bourdieu. Desde la perspectiva que ofrecemos aquí, sin embargo, la narrativa no desafía a la objetividad por medio de la objetivación del sujeto objetivante (Knafo, 2016), sino navegando la imposibilidad de objetivar a secas cuando del mundo humano se trata y esto incluye al yo que escribe. La sociologización de sí ofrece una tranquilizadora ilusión de control que reproduce la escritura fortaleza; pero, complementariamente, la apertura al otro referida en el párrafo anterior también es incompatible con lo que se puede llamar subjetivismo. La voz narrativa contrasta con una epistemología de lo puramente singular, incriticable en su subjetividad radical. Esto es más controversial de lo que puede parecer 
a primera vista, porque supone remover la ilusión de que hay sujetos que por su sufrimiento o experiencia- no pueden ser cuestionados. Este punto será expandido en el cierre del artículo. Por ahora, interesa subrayar que toda narrativa es criticable, incluso la de quienes hablan de su propia experiencia o desde un lugar de subalternidad. ${ }^{7}$ Esto es muy importante porque es en el espacio de encuentro y cuestionamiento donde se forjan nuevos sentidos y emergen nuevas formas de pensar. ${ }^{8}$

En contraste con la escritura fortaleza, la voz narrativa no puede ofrecer argumentos claros, lineales y contundentes. Los significados de una historia son ingobernables y ni siquiera pueden ser fijados de una vez y para siempre por quien escribe. El resultado es siempre la multiplicidad de versiones y sentidos. Pero, además, los instrumentos propiamente «científicos» son constantemente desbordados por la realidad que tratan de aprehender. Los científicos más sofisticados — que no son los cientistas sociales más apegados a la escritura fortaleza, por cierto- suelen enfatizar lo limitado que es nuestro saber sobre los más diversos temas, desde el cerebro humano hasta el funcionamiento del universo. Además de ponerle contenido a las abstracciones de la ciencia, la narrativa puede hacerse cargo de cómo la vida social desborda sus cajas clasificatorias. En lugar de fijar, desarrollar y defender una posición, la forma literaria puede ofrecer modos de navegar la polisemia, así como las limitaciones de nuestro conocimiento: ¿no es ésta, acaso, una función epistemológica, política e incluso «humana», específica e importante, que abriga además una dimensión democrática? Presentar argumentos claros y contundentes no es la única forma de escribir, investigar o pensar.

En lugar de extraer evidencias y probar verdades, las narrativas traen diversas formas epistemológicas de ser en el mundo. Y en vez de cosificarlas, les otorga permiso de existencia en la escritura. Esto enriquece la forma de

\footnotetext{
${ }^{7}$ Las narrativas publicadas en relaciones internacionales usualmente muestran cuán relativa, limitada, arbitraria e incluso «rota» es la posición del escritor (Öberg, 2016; Kirby, 2016; Smith-McGregor, 2016; Hite y Huguet, 2016).

${ }^{8}$ La ilusión de objetividad y lo que hemos denominado subjetivismo son más parecidos de lo que parece: ambos reifican a un yo a-problemático y transparente, borrando la intersubjetividad del conocimiento y del mundo. Ambos perpetúan la ilusión de control y pureza: la escritura fortaleza concibiendo al yo como capaz de vaciarse de emociones y el subjetivismo validando posiciones políticas o normativas por medio de las emociones. Las dos perspectivas anulan el encuentro con el otro, colocando la voz del escritor en un lugar inaccesible e impidiendo el diálogo con el lector. En otras palabras: se trata de dos caras del mismo autoritarismo. Las narrativas, en contraste, ubican el proceso mismo de su producción $\mathrm{y}$ al sujeto escribiente, en un lugar al que el lector puede acceder para hacer preguntas y pedir cuentas.
} 
conocer y, por tanto, también amplía las posibilidades de la academia. En su cuestionamiento a las reificaciones de la ciencia, la narrativa invita a un pluralismo radical (Levine y McCourt, 2018) que incluye la pluralización del (modo de entender al) conocimiento en sí mismo. La voz narrativa complica las respuestas a las preguntas de qué significa conocer, qué conocimiento es válido y cómo debe conocerse. Esto obviamente compromete a las métricas de éxito, fracaso y excelencia de la investigación académica, y suspende cualquier criterio rígido o definitivo.

La evaluación de un producto narrativo no puede ser resuelta con rúbricas o puntajes prestablecidos, sino que requiere conversación, exploración e interpretación. Probablemente eso no le haga mal a la academia. Por ejemplo, a estas alturas está bien establecido que la escritura académica debe ser clara y precisa. No nos oponemos a ello y entendemos las ventajas de la claridad y la precisión en el lenguaje, ipero qué tipo de disciplinamiento al pensamiento puede traficarse en nombre de la correcta prosa académica? ¿No habrá experiencias y exploraciones que demandan escribir de otra forma, quizá con pausas, iteraciones, dubitaciones y otros momentos incómodos para nuestros estándares de excelencia? La narrativa permite habitar esta pregunta sin censura previa.

En contraste con la ilusión de transparencia lingüística propia de la escritura fortaleza, la voz narrativa revela que todos somos perpetuos inmigrantes en el lenguaje. El intento de nombrar, sintetizar, clasificar y entender falla una y otra vez. Y fallamos incluso - o especialmente- en traducir nuestras experiencias a otros. Por tanto, las narrativas habitan de forma activa tanto los límites del lenguaje como su poder. Revelan, asimismo, el complejo rol que tiene la ficción en la vida personal y social, así como en cualquier versión de la realidad, incluyendo la científica. Al fin y al cabo, todos contamos historias a través de conceptos, formulas o números que -en el caso de la escritura fortaleza- ficcionalizan la ausencia de ficción.

Si bien aquí hay coincidencia con Sarah Naumes (2015) en que la narrativa es más que «buena escritura», es la noción de buena escritura en sí misma lo que queda en suspensión. Además, la dimensión estética puede ser entendida en un sentido fuerte como el modo en que un texto organiza una parcela de lo sensible y de lo político; piénsese, por ejemplo, en el poder de las imágenes literarias y las metáforas para movilizar conceptos, en las múltiples capas de una historia que llevan a crear pensamiento nuevo, o en 
la rumia poética que termina aventurándose en lo filosófico. El aspecto lúdico de la escritura y el placer de escribir y leer —exiliados de la academiavuelven como pasajeros legales de la narrativa. ${ }^{9}$

En lugar de centrarse en el control, tal como se habitúa, la voz narrativa navega la ambigüedad y la contradicción. Por tanto, le ofrece a la academia una oportunidad para dejar de ignorar un inmenso espectro de experiencia. Algunos trabajos narrativos dan cuenta del poder deconstructivo de la sorpresa, de esa sorpresa que por radical nos desarma. El término «desarmar» opera aquí en los dos sentidos de desafiar la idea que se tiene de quiénes somos, cómo es el mundo y qué hacemos en él, y de quitarnos las armas. En lugar de ser una amenaza para la propia reputación o un evento humillante, la sorpresa así entendida es una oportunidad para pensar de otro modo. En otras palabras, la vulnerabilidad deviene una capacidad. La falta de un método prefijado es un límite, pero también un posibilitador.

En el apartado anterior se señaló que la escritura fortaleza segmenta la realidad en dimensiones — cultura, economía, sociedad, entre otros-. El marxismo y otros enfoques teóricos críticos han señalado que concebir dicha separación como propiedad de la realidad misma —es decir, reificarla— es

[248 ] una operación cargada de ideología o que, de hecho, es ideología dominante en operación (Gramsci, 2008; Bannerji, 2005). Piénsese, por ejemplo, en la democracia. Para el mainstream de la ciencia política en América Latina, no importa si hay fuerzas y relaciones sociales que convierten a la democracia en una cáscara vacía. Lo determinante es que las instituciones formales del sistema político estén funcionando. Es precisamente la división artificial entre política y sociedad lo que permite pensar a la democracia como un mero arreglo institucional. Las narrativas políticas juntan lo que el análisis politológico separa. ${ }^{10}$ Manuela Picq (2016), por ejemplo, muestra que cuando se tienen en cuenta los distintos aspectos de la vida de la gente la frontera entre democracia y autoritarismo no queda tan clara. Lo político es más movedizo, rico y contradictorio que las abstracciones con las que

\footnotetext{
${ }^{9}$ Nótese, sin embargo, que el argumento no niega que la escritura fortaleza genere placer. La capacidad de dominar los códigos académicos y de demostrar que se está en lo correcto dan sensación de poder. Tampoco niega el disfrute de escribir y leer excelente prosa académica. Dauphinee (2013) explora este tema. El punto refiere a la dimensión lúdica y colegial que sí se pierde en la escritura fortaleza.

${ }^{10}$ Narrar historias rescata la experiencia humana de la simplificación. Esto puede expresarse también en lenguaje marxista: contra la abstracción violenta y el valor de intercambio, la voz narrativa trae de vuelta al valor de uso, sacudiendo concepciones «literales» — y literalizantes - de las divisiones impuestas por las ciencias sociales modernas.
} 
categorizamos sistemas o entidades. El trabajo, escrito en español y publicado por una revista de teoría política uruguaya, narra la expulsión de Picq de Ecuador por el gobierno de Rafael Correa y, mientras tanto, explora aspectos significativos de este. El texto ejemplifica así el potencial de la voz narrativa para explorar la política latinoamericana.

Además de mostrar sus limitaciones, las narrativas politizan la academia. Esta es narrada como lo que es: un lugar donde hay relaciones de poder. Muchas narrativas en primera persona se centran en explorar cómo la vida en la universidad es afectada por las mismas formas de opresión que se detectan «afuera». El sexismo y el racismo, por ejemplo, se manifiestan en el aula, en los departamentos académicos y en nuestras teorías, incluso las críticas, marcando trayectorias profesionales y estableciendo jerarquías y diferencias de prestigio; pero, además, estas relaciones de poder administran los análisis que se pueden hacer y los que no, dictando incluso los temas de lo que se puede hablar. En estos tiempos de rebelión antirracista, es importante recordar que la ciencia política norteamericana en sus orígenes pensó la democracia de modos ideológicamente entroncados en la supremacía blanca y que durante buena parte siglo xx la disciplina tuvo ingentes dificultades para entender al racismo como un problema político (Blatt, 2018). La relevancia de estas cuestiones en el contexto de la academia latinoamericana resulta evidente.

Esta crítica a la injusticia no es solo «estructural», sino que además requiere que el académico enfrente su propia implicación y complicidad en ella. Esto también incluye a quienes se perciben a sí mismos como sujetos oprimidos. Después de todo, los oprimidos participan de distintos modos en su propia opresión y generalmente también oprimen a alguien (Ravecca, 2019). Se debe aclarar que identificar el propio rol en la injusticia no significa exagerarlo o, mejor dicho, significa tener el cuidado de no exagerarlo. De hecho, exagerar la importancia del propio «privilegio», que se ha vuelto un cliché en algunos círculos, es un modo activo de ignorar la propia insignificancia y de insistir en la singularidad o importancia de la propia experiencia. ${ }^{11}$

Las narrativas brindan la oportunidad de poner la crítica ahí, donde duele, desafiando la autopercepción ética del narrador, sea en tanto analista objetivo, héroe de la justicia social, o protagonista central de las relaciones

${ }^{11}$ El objetivo de conectar con el mundo y con los demás es empañado por el narcisismo. 
de poder contemporáneas. Los académicos no somos ni tan objetivos, ni tan bondadosos, ni tan importantes...

La voz narrativa incluye a los «otros» de la ciencia: sentimientos, intuiciones, espiritualidad, saberes populares, voces fragmentadas, la locura misma. Este aflojamiento de las fronteras de lo permitido puede hacer que la academia devenga en menos dogmática, menos opresiva y mejor en lo que fundamentalmente trata de hacer: entender el mundo social. El carácter reaccionario que a veces toma la identidad de las ciencias sociales no implica necesariamente mayor excelencia o profundidad. La habilitación a explorar distintas formas de saber tampoco implica ingresar en un terreno donde todo vale. En ausencia de un conjunto prefijado de normas que deciden qué es válido y qué no, la lectura del texto cobra un sentido crucial de interlocución y crítica.

En efecto, las narrativas replantean completamente el vínculo entre texto y lectura en el contexto académico. Las contribuciones de una narrativa son inseparables de la interpretación que propone el lector o lectora. El resultado en términos de reflexión o de conocimiento se define en ese encuentro con otro y, por tanto, es colectivo. Paradójicamente, tratándose de un enfoque que

[250 ] recoge la experiencia personal, la contribución narrativa está menos centrada en el ego y requiere del otro para activarse. Esto puede revertir tendencias indeseables en el mundo narcisista de la teoría crítica que replican de formas inesperadas el individualismo metodológico y meritocrático del liberalismo. Las narrativas son completadas por la lectura y pueden ser rescatadas, sorprendidas e incluso «re-escritas» por sus lectores. Sus fallas constituyen posibilidades para un encuentro pedagógico que es la imagen invertida de la escritura fortaleza y sus encuentros bélicos. La voz narrativa expande el espacio para la generosidad (Ravecca y Dauphinee, 2018).

Si se empuja la idea del rol activo de la lectura hasta sus últimas consecuencias, se encuentra con que la narrativa es el resultado del modo en que el texto es leído. La narrativa hace su tarea en el momento en que es criticada o deconstruida por otros.

\section{A modo de conclusión: tres riesgos de la escritura narrativa}

En este artículo hemos comparado la voz narrativa con la escritura fortaleza, a la cual conceptualizamos como el estilo dominante de escritura en la ciencia política y las relaciones internacionales. Nos contamos entre 
quienes están cansados de los aspectos violentos del debate académico y consideramos que la voz narrativa puede abrir alternativas. Nuestro ejercicio, sin embargo, tuvo una limitación significativa: al organizar la reflexión en términos de modelos teóricos o tipos ideales incurrió en cierta simplificación y binarismo. No concebimos a los enfoques narrativos como una panacea y nos gustaría dejar planteadas para la discusión futura algunas formas de violencia excluyente que estos pueden ejercer.

A continuación, se presentan brevemente tres riesgos de la escritura narrativa que demandan más indagación: el apego a la inocencia, el apego al trauma y la cancelación moralizante de la complejidad. Cada uno a su manera remite a lo que antes denominamos subjetivismo, así como al dogmatismo y al autoritarismo que pueden colarse en el lenguaje de la justicia social. Más que expedirnos acerca de si textos con estas características deben ser publicados o no — suelen serlo_ hacemos un llamado a redoblar el ímpetu autocrítico y a problematizar la resistencia a la complejidad que — tambiénse manifiesta en los intentos de escribir narrativamente. En lugar de hacer un listado de textos que desde nuestra perspectiva presentan estas limitaciones, mencionamos algunos ejemplos que las trascienden y que a nuestro juicio logran habitar la voz narrativa.

\section{Apego a la inocencia}

Es siempre tentador colocarse del lado de las víctimas, los buenos, los puros, los oprimidos y los éticos, incluso cuando supuestamente estamos realizando un ejercicio de autocrítica. Consideramos que este apego a la propia inocencia - personal o colectiva - constituye una barrera para la reflexión y, en particular, para el desmantelamiento analítico de las relaciones de poder. La ceguera en torno al rol propio en la opresión la refuerza - a veces, en nombre de «la resistencia»- Este es un problema muy serio y persistente en las ciencias sociales alternativas y en especial en la producción narrativa. La escritura fortaleza, por su parte, codifica su apego a la inocencia en términos de la neutralidad y la objetividad científicas.

Uno de los límites más severos de la teoría crítica es que no cuenta con el lenguaje para nombrar el horror del cual somos partícipes en este preciso momento. Encontrar dicho lenguaje supone poder colocarse en el lugar del opresor. Declarar nuestros «privilegios» es inútil. Es necesario más bien explorar los beneficios y placeres que se obtienen cada día a través de la opresión de otros. Hay narrativas que encaran esta desafiante tarea. 
Dauphinee (2013), por ejemplo, examina cómo su posición como académica no dista tanto de la del criminal de guerra como pareciera a primera vista. Kevin Dunn (2016) descubre su propio racismo. Otras narrativas hacen ejercicios similares en torno a temas como la inmigración (Doty, 2015) y el terrorismo (Edkins, 2016). Öberg (2016), por su parte, muestra que «radical» es una mercancía que él vende cotidianamente a sus estudiantes, así como Starbucks vende café.

\section{Apego al trauma}

La escritura narrativa permite explorar la dimensión subjetiva de la política y del poder, y suele lidiar con experiencias dolorosas y traumáticas. Esto puede constituir una oportunidad de crecimiento y creación, pero no hay garantía de que ello ocurra. El trauma puede extenderse indefinidamente. El dolor y la ira, entre otras emociones similares, pueden traducirse en el maltrato a otros y en formas de autoritarismo intelectual. La crítica para ser generosa, abierta y constructiva precisa significar y procesar el trauma, trascendiendo el género confesional y la mera catarsis ateórica (Ravecca y Dauphinee, 2018).

No hay una receta única sobre cómo hacer esto. Por ello volvemos a las [252] interrogantes planteadas en Ravecca (2019b, p. 401): «¿Qué significa narrar dolor y experiencias de abuso manteniendo un tratamiento ético del abusador? O sea, ¿cómo no abusar al abusador en nuestra escritura?». Si esto no es posible, es importante reconocerlo y examinarlo como hace contundentemente Saoirse O'Shea (2019). Evidentemente el punto tiene ramificaciones significativas no solamente para el análisis crítico y la subjetividad, sino también para la praxis democrática y para cómo narrar afrentas y daños colectivos. Planeamos abordar estas conexiones sistemáticamente en trabajos futuros.

\section{Cancelación moralizante de la complejidad}

Como mencionamos antes, es tentador contarse entre los buenos. Nadie quiere estar en el lado equivocado de la historia. Pero una de las consecuencias de este deseo es la persistente tendencia a la negación de la complejidad. El compromiso con la justicia puede devenir, como lo ha hecho muchas veces, en reduccionismo dogmático. Por ello la arrogancia ética es peligrosa tanto en la política como en el pensamiento. Cuando las narrativas hacen su trabajo crítico es porque sospechan de la propia inocencia, elaboran el trauma para crear algo nuevo y abren la escritura a la complejidad moral de las relaciones de poder (Sosa, 2016, septiembre 16). 
Posibilidades y riesgos de la narrativa en relaciones internacionales y ciencia política

\section{Referencias bibliográficas}

1. Adorno, Theodor W. (1994). Dialéctica negativa. Madrid: Taurus.

2. Bannerji, Himani. (2005). Building from Marx: Reflections on Class and Race. Social Justice, 32 (4), pp. 144-162.

3. Blatt, Jessica. (2018). Race and the Making of American Political Science. Philadelphia: University of Pennsylvania. https://doi.org/10.9783/9780812294897

4. Brigg, Morgan y Bleiker, Roland. (2010). Autoethnographic International Relations: Exploring the Self as a Source of Knowledge. Review of International Studies, 36, pp. 779-798. https://doi.org/10.1017/S0260210510000689

5. Brown, Wendy. (1995). States of Injury: Power and Freedom in Late Modernity. Princeton: Princeton University. https://doi.org/10.1515/9780691201399

6. Brown, Wendy. (2011). La teoría política no es un lujo: una respuesta a «La teoría política como profesión» de Timothy Kaufman-Osborn. Crítica Contemporánea, 1, pp. 1-9.

7. Burnier, DeLysa. (2006). Encounters with the Self in Social Science Research: A Political Scientist Looks at Autoethnography. Journal of Contemporary Ethnography, 35 (4), pp. 410-418. https://doi.org/10.1177/0891241606286982

8. Clare, Eli. (2017). Brilliant Imperfection. Grappling with Cure. Durham: Duke University. https://doi.org/10.1515/9780822373520

9. Dauphinee, Elizabeth. (2013). The Politics of Exile. New York: Routledge. https://doi.org/10.4324/9780203077986

10. Dauphinee, Elizabeth y Inayatullah, Naeem (Eds.). (2016). Narrative Global Politics. London: Routledge.

11. Doty, Roxanne Lynn. (2015). A Mostly True Day in Eloy, Arizona. Journal of Narrative Politics, 2 (1), pp. 22-24.

12. Dunn, Kevin C. (2016). What Might Still Sputter Forth. En: Dauphinee, Elizabeth \& Inayatullah, Naeem (Eds.). Narrative Global Politics (pp. 139-152). London: Routledge.

13. Edkins, Jenny. (2016). Loss of a Loss: Ground Zero, Spring 2014. En: Dauphinee, Elizabeth y Inayatullah, Naeem (Eds.). Narrative Global Politics (pp. 97103). London: Routledge.

14. Giroux, Henry. (2014). Neoliberalism's War on Higher Education. Chicago: Haymarket.

15. Gramsci, Antonio. (2008). Selections from the Prison Notebooks. New York: International Publishers. https://doi.org/10.2307/j.ctv120qr2d.14

16. Hite, Katherine y Huguet, Jordi. (2016). Luz guía. Crítica Contemporánea, 6, pp. 43-52.

17. Horkheimer, Max. (1978). Théorie critique. Paris: Payot.

18. Jackson, Patrick Thaddeus. (2011). The Conduct of Inquiry in International Relations: Philosophy of Science and its Implications for the Study of World Politics. London: Routledge. 
19. Inayatullah, Naeem (Ed.). (2011). Autobiographical International Relations: I, IR. New York: Routledge. https://doi.org/10.4324/9780203837221

20. Inayatullah, Naeem. (2020, May 4). Internal Simultaneity: A Science of Autobiography. E-International Relations. https://www.e-ir.info/2020/05/04/opinioninternal-simultaneity-a-science-of-autobiography/

21. King, Gary, Keohane, Robert O. y Verba, Sidney. (2000). El diseño de la investigación social: la inferencia científica en los estudios cualitativos. Madrid: Alianza.

22. Kirby, Paul. (2016). AUTO/BIO/GRAPH. En: Dauphinee, Elizabeth y Inayatullah, Naeem (Eds.). Narrative Global Politics (pp. 153-158). London: Routledge.

23. Knafo, Samuel. (2016). Bourdieu and the Dead End of Reflexivity: On the Impossible Task of Locating the Subject. Review of International Studies, 42 (1), pp. 25-47. https://doi.org/10.1017/S0260210515000121

24. Levine, Daniel J. and McCourt, David M. (2018). Why Does Pluralism Matter When We Study Politics? A View from Contemporary International Relations. Perspectives on Politics, 16 (1), pp. 92-109. https://doi.org/10.1017/ S1537592717002201

25. Marcuse, Hebert. (1991). One-Dimensional Man: Studies in the Ideology of Advanced Industrial Society. Boston: Beacon.

26. Marx, Karl. (1978). Economic and Philosophic Manuscripts of 1844. En: Tucker, R. C. (Ed.). The Marx-Engels Reader (pp. 66-125). New York: W. W. Norton [254] \& Company.

27. Mohanty, Chandra Talpade. (2013). Transnational Crossings: on Neoliberalism and Radical Critique. Signs, 38 (4), pp. 967-991. https://doi.org/10.1086/669576

28. Monroe, Kristen Renwick. (2005). Perestroika! The Raucous Rebellion in Political Science. New Haven: Yale University.

29. Naumes, Sarah. (2015). Is All «l» IR? Millennium-Journal of International Studies, 43 (3), pp. 820-832. https://doi.org/10.1177/0305829815576820

30. Nietzsche, Friedrich. (1989). Genealogy of Morals. New York: Vintage.

31. Öberg, Dan. (2015). Violent Fragments. Journal of Narrative Politics, 1 (2), pp. $150-152$.

32. Öberg, Dan. (2016). Tomorrow the War Starts. Journal of Narrative Politics, 2 (2), pp. 169-175.

33. O'Shea, Saoirse C. (2019). My Dysphoria Blues: Or Why I Cannot Write an Autoethnography. Management Learning, 50 (1), pp. 38-49. https://doi. org/10.1177/1350507618791115

34. Picq, Manuela L. (2016). El caminar de las manuelas. Crítica Contemporánea, 6, pp. 124-138.

35. Pin-Fat, Véronique. (2016). Dissolutions of the Self. En: Dauphinee, Elizabeth y Inayatullah, Naeem (Eds.). Narrative Global Politics (pp. 25-34). London: Routledge. 
36. Ravecca, Paulo. (2019a). The Politics of Political Science: Re-Writing Latin American Experiences. London \& New York: Routledge. https://doi. org/10.4324/9781351110556

37. Ravecca, Paulo. (2019b). Respuesta a Jerónimo Ríos Sierra y Diego Rossello. Eunomía, 17, pp. 394-403. https://doi.org/10.20318/eunomia.2019.5044

38. Ravecca, Paulo y Dauphinee, Elizabeth. (2018). Narrative and the Possibilities for Scholarship. International Political Sociology, 12 (2), pp. 125-138. https://doi. org/10.1093/ips/olx029

39. Ravecca, Paulo y Dauphinee, Elizabeth. (2016). Narrativa (y) política: ideas que solo se pueden contar. Critica Contemporánea, 6, pp. 1-4.

40. Ravecca, Paulo y Rossello, Diego. (2020). Deconstruyendo el yo disciplinar: el vínculo entre ciencia política y teoría política en América Latina. Civilizar, 20 (39), pp. 115-125. https://doi.org/10.22518/jour.ccsh/2020.2a07

41. Rieiro, Anabel; Rinesi, Eduardo y Ravecca, Paulo. (2019). Pensamientos críticos. Revista de Ciencias Sociales, 32 (44), pp. 9-13.

42. Smith-McGregor, Kilby. (2016). Seeing Red. Crítica Contemporánea, 6, pp. 118-123.

44. Sosa Villada, Camila. (2016, septiembre 16). Pobres y estúpidos niños ricos. La Tinta. https://latinta.com.ar/2016/09/pobres-y-estupidos-ninos-ricos/

45. Traversa, Federico. (s. f.). Maquiavelo y el arbitraje doble ciego (especulación inédita). Academia.edu. https://www.academia.edu/10735317/Maquiavelo_y_el_ arbitraje_doble_ciego_especulaci\%C3\%B3n_in\%C3\%A9dita_ 